\title{
Proceeding
}

Supplementary Issue: Winter Conferences of Sports Science. VI International Congress and XXVII National Congress of Physical

Education, 23-25 October 2019. Palma (Baleares), Spain.

\section{Analysis of parental behaviour and attitude in sports and its relation with the sports performance}

\author{
ELISA ISABEL SÁNCHEZ-ROMERO 11 , FRANCISCO JAVIER PONSETI-VERDAGUER², DAVID \\ PULIDO², PERE ANTONI BORRÀS² \\ ${ }^{1}$ Department of Social, Legal and Business Sciences, Catholic University of Murcia (UCAM), Murcia, Spain \\ ${ }^{2}$ Department of Pedagogy, University of the Balearic Islands, Palma (Mallorca), Spain
}

\begin{abstract}
The aim of the present investigation was to analyse the relation between parental behaviour and other sociodemographic and sportive variables with their children's sports performance. A sample of 223 parents (46.2\% men; $53.4 \%$ women) of 223 youth athletes $\left(77.13 \%\right.$ boys; $22.87 \%$ girls; $M_{\text {age }}=11.66$ years; $\left.D E=1.60\right)$ were asked. All of them belonged to 13 grassroots teams: football (soccer) $(48.9 \%)$, basketball $(13.5 \%)$, volleyball (34.1\%) and handball (3.6\%) of different categories: U-12 (36.8\%), U-13 (48\%) and U-15 (15.2\%). A retrospective ex post facto design of unique group was planned. The questionnaire Análisis del Comportamiento y Actuación de los Padres y Madres en el Deporte (ACAPMD) was used. Differences statistically significant were detected between parental behaviour to the sports, socio-demographic variables (age and athlete's gender, parents' gender and geographical zone) and sports variables (sports category and sport played) with the sports performance. An age increase above the mean, it will make more probable a high sports performance. The clubs of out of Palma registered the highest percentage of sports performance and low sports performance. The highest percentage of high performance was registered in men and women highlighted in medium and low performance. The highest percentages of high and medium performance were registered when the mothers answered the questionnaire. The highest percentage of high and low performance was registered in basketball. And, the highest percentage of sports performance was in U-12's category, U-13's category highlighted in low performance and U-15's category highlighted in medium performance.
\end{abstract}

Keywords: Youth sport; Family behaviour; Sports agents; Physical education.

Cite this article as:

Sánchez-Romero, E.I., Ponseti-Verdaguer, F.J., Pulido, D., \& Borràs, P.A. (2020). Analysis of parental behaviour and attitude in sports and its relation with the sports performance. Journal of Human Sport and Exercise, 15(2proc), S327-S335. doi:https://doi.org/10.14198//hse.2020.15.Proc2.24

Corresponding author. Department of Social, Legal and Business Sciences, Catholic University of Murcia (UCAM), Campus de los Jerónimos, s/n, CP: 30107. Murcia. Spain. https://orcid.org/0000-0001-5589-2235

E-mail: eisanchez@ucam.edu

Supplementary Issue: Winter Conferences of Sports Science. VI International Congress and XXVII National Congress of Physical Education, 23-25 October 2019. Palma (Baleares), Spain.

JOURNAL OF HUMAN SPORT \& EXERCISE ISSN 1988-5202

(C) Faculty of Education. University of Alicante

doi:10.14198/jhse.2020.15.Proc2.24 


\section{INTRODUCTION}

In recent decades, parents have increased their interest and active involvement into their children's sport events (Strandbu, Stefansen, Smette and Renslo-Sandvik, 2017; Witt and Dangy, 2018). Nonetheless, parents are focused on seeking emotional closeness and a reciprocal relationship with their children and comprehend themselves as responsible for all aspects of their development (Strandbu et al., 2017).

Therefore, the sport is understood as a social phenomenon that is in constant expansion, and where unfortunately, many times it is created an interest about the competition and for obtaining results (Pulido, Borràs y Ponseti, 2019). In the sportive context exists a widespread belief that most of the obtained results come thanks to mental factors, and from the empiric evidence, various studies demonstrate that athletes' psychological characteristics are related to their performances in sports like Olympic wrestling (López-Gullón et al., 2012; Pallarés, López-Gullón, Torres-Bonete and Izquierdo, 2012), football (soccer) (Gómez-Díaz, Pallarés, Díaz and Bradley, 2013) and handball (Martínez-Moreno, 2017).

Thus, when a young athlete decides to develop his or her talent to reach elite status, it will trigger different consequences for lifestyle. It is emphasized that all socio-educational agents in sport play an important role to accomplish it, but particularly parents (Visscher, Elferink-Gemser and Lemmink, 2009).

Parental support is directly related to the previous mental factors which influence into athletes' performances. Thus, parental support is shown as a crucial item to ensure sports success (González-García, 2017; Rachele, Cuddigy, Washington and McPhail, 2016). Hohepa, Scragg, Schofield, Kolt and Schaaf (2007) point that when the support is perceived positively and in appropriate quantity, the player feels that his environment presents a favourable attitude towards the sport and physical activity.

Consequently, it is necessary that parents present a positive support towards their children's sportive practice, from the beginning of their sports events until the end. By this way, there are investigations which mention that the most successful athletes received more support by their parents (Simón, 2009; Visscher, Elferink-Gemser and Lemmink, 2009).

Visscher et al. (2009) highlighted that over $90 \%$ of parents were seen as a role model for sport participation, and that over $75 \%$ of parents provided at least emotional support regarding their children's sport involvement. These authors pointed that families of successful players provided a truly positive sport environment; parents of more talented athletes provided better role models for their sons' sporting achievements and more positive reinforcement toward better sport achievements.

In addition, there are investigations which have been focused onto manifest differences between gender's player and the influence of their sports performances. Fradejas and Espada-Mateos (2018) affirm that men manifest higher levels of control over the influence of their own performances. Furthermore, same authors point that women are more concerned about their performances, which could be explained throughout high levels of competitive anxiety and low levels of self-confidence (Caputo, Rombaldi and da Silva, 2017; Fradejas and Espada-Mateos, 2018). Moreover, González, Campos and Romero (2014) found that more than two thirds $(68 \%)$ of young footballers affirm that they were affected by negative external evaluations about their mistakes or performances.

Likewise, it is highlighted the existence of studies, which do not only pretend to underline the importance of the family into the sports performance but establishing differences between different types of familiar 
structures (González-García and Pelegrín, 2018). These authors do not find significant differences between single-parent family and bi-parental families related to become a professional athlete. It is also remarkable that González-García and Pelegrín (2018) do not find relation between performance level, successful level in sports and familiar structure.

According to Visscher et al. (2009) the influence of the family at each stage of a youth athlete's development needs consideration to comprehend the relation between family dynamics and the athlete's performance. Consequently, it is required to analyse the abovementioned relation and other socio-demographic and sportive variables.

The main aim of the present study was to analyse the relation between the behaviour and attitude of fathers and mothers of grassroots teams' players and other socio-demographic variables (geographical area, players' gender, parents' gender) and sportive (sports club, played sport, sports category) with players' performance.

The initial hypothesis is that exists a relation between parental behaviour and attitudes of parents of grassroots sports' players and other socio-demographic and sportive variables with athletes' performance.

\section{MATERIALS AND METHODS}

\section{Participants}

The sample was formed by 223 parents ( $46.2 \%$ men; $53.4 \%$ women) by 223 youth athletes of both genders (172 boys, $77.13 \%$; 51 girls, $22.87 \%)$, in the $9-15$ age range $(M=11.66$ years; $S D=1.597)$. All the athletes belonged to 13 sports clubs (62.8\% of Palma; $37.2 \%$ out of Palma), of four grassroots sports: football (soccer) (48.9\%), basketball $(13.5 \%)$, volleyball $(34.1 \%)$ and handball $(3.6 \%)$ and were divided into different sports categories: U-12 (36.8\%), U-13 (48\%) and U-15 (15.2\%).

\section{Instruments}

For measuring the variables of the study, a notebook with the used questionnaire and a series of questions was provided to the participant parents for collecting socio-demographic data (geographical zone, age and gender) and sports data (sports club, sport played, sports category and sports performance).

Análisis del Comportamiento y Actuación de Padres y Madres en el Deporte (ACAPMD; Garrido, Zagalaz, Torres y Romero, 2010). This instrument measures, throughout 44 items, 7 dimensions related to the parental behaviour in their children's' sport: 1) The relationship between parents and coach; 2) Level of satisfaction with the coach's work; 3) Sports relationship between parents and child; 4) Level of involvement of parents in their children's sports life; 5) Parental conduct during the match; 6) Parental interest and expectations related to the competition; and 7) Value and importance that parents provide to the Municipal Sports Schools. The response scale was a 5-point Likert-type with values which were from 1 (No, nothing) to 5 (Yes, a lot or Yes, always). Some of the reliability Cronbach's alfa were obtained (intern consistency) per sections: $a=.83$ for the parents-coach relationship; $a=.66$ for parental conduct during the matches; $a=.73$ for the interest and expectations. These results are quite similar to the obtained by Garrido et al. (2010), for the sports relationship between parents and coach $(\alpha=.86)$; for the parental conduct in matches $(a=.79)$; and for the interest and expectations $(a=.81)$. 


\section{Procedure}

The permission to carry out this investigation was provided by the local government (Govern de les Illes Balears, Spain) throughout its project called Posam Valors a l'Esport. Moreover, the department of Physical Education and Sports of the University of the Balearic Islands (UIB) contacted with different federations for obtaining the permissions of this entity and its sports clubs.

After explaining the main aims of this study to the participants, the timetable to apply the notebook was established. A standardized procedure was used for guaranteeing that the instructions were the same for all the participants. It is highlighted that previously, parents signed their collaboration with the study.

\section{Statistical Analysis}

All the statistical analyses were executed with IBM SPSS, version 22.0 for Windows operating system. An initial description was performed about the study variables, and for that, descriptive statistics were calculated (mean and standard deviation) and frequencies. Pearson's X2were calculated to compare the associations and distributions of categorical variables in the sports performance. Furthermore, a discriminant analysis was performed aimed to classify the athletes into established groups for the sports performance variable, from quantitative variables (athletes' age and dimensions of ACAPMD).

\section{Design}

For the purpose of the present study, a retrospective ex post facto design of unique group was planned (León and Montero, 2003), in which the parental support in sports practice and other social-demographic and sportive variables were measured about the performance of young players in grassroots sport. This kind of design is very useful as a way of approaching to the study of concrete problems which could not been investigated from other methods, due to its complexity and nature of the implied variables. Furthermore, the retrospective ex post facto designs focus their aims onto the study of the existent relationship between the variables, enabling the implementation of a predictive model (García-Gallego and Rubio de Lemus, 2010).

\section{Ethical Considerations}

The present investigation analyses the behaviour and attitudes of humans and, for this reason it must accomplished with the ethical principles of respect to the human dignity, the confidentiality and nondiscrimination. A favourable inform has been obtained about the realization of this study by the ethical committee of the University of the Balearic Islands (UIB - 93CER18). Thus, the study was performed in accordance with the Declaration of Helsinki of 1975 reviewed in 2000.

\section{RESULTS}

\section{Socio-demographic variables and its relation with the sports performance}

Regarding the age, the discriminant analysis revealed a positive relation between the age and the sports performance: high ( $M=11.18 ; \mathrm{DE}=1.21)$, medium $(\mathrm{M}=11.93$; $\mathrm{DE}=1.70)$ and low $(\mathrm{M}=11.89 ; \mathrm{DE}=1.78)$, observing statistically significant differences (Lambda Wilks $=.95, \chi 2(2)=11.01 ; p<.05)$. Therefore, an age increasement, above the mean, it will make more probable a high sports performance.

The sports performance breakdown according to the geographical zone (Table 1) revealed statistically significant differences in the sports performance pattern according to the clubs belonging to Palma or out of Palma (Pearson's $X 2(2)=21.33, p<.001$; Cramer's $V=.31$ ). The clubs of out of Palma registered the highest percentage of sports performance $(53.01 \%)$, while the highest percentage of the medium sports performance 
in Palma (53.57\%) and finally, the lowest percentage of low sports performance was in the clubs of out of Palma (7.23\%).

Table 1. Frequencies and percentages of the sports performance variable according to the geographical zone.

\begin{tabular}{lccc}
\hline & \multicolumn{3}{c}{ Geographical zone* } \\
\hline Performance & Palma & Out of Palma & Total \\
\hline High & $34(24.29 \%)$ & $44(53.01 \%)$ & $78(34.98 \%)$ \\
Medium & $75(53.57 \%)$ & $33(39.76 \%)$ & $108(48.43 \%)$ \\
Low & $31(22.14 \%)$ & $6(7.23 \%)$ & $37(16.60 \%)$ \\
Total & $140(62.78 \%)$ & $83(37.22 \%)$ & 223 \\
\hline \multicolumn{4}{c}{ Note: ${ }^{*} n(\%)}$.
\end{tabular}

Regarding to the athletes' gender, some statistically significant differences were observed about the obtained performance being a man or a woman (Pearson's $x 2(2)=23.27, p<.001$; Cramer's $V=.32$ ). Accordingly, it was registered a higher percentage of high performance in men $(43.02 \%)$, while women outnumbered men in medium performance $(62.74 \%)$ and low $(29.41 \%)$ (Table 2).

Table 2. Frequencies and percentages of sports performance variable according to the athlete's gender.

\begin{tabular}{lccc}
\hline & \multicolumn{3}{c}{ Athlete's gender } \\
\hline Performance & Men & Women & Total \\
\hline High & $74(43.02 \%)$ & $4(7.84 \%)$ & $78(34.98 \%)$ \\
Medium & $76(44.19 \%)$ & $32(62.74 \%)$ & $108(48.43 \%)$ \\
Low & $22(12.80 \%)$ & $15(29.41 \%)$ & $37(16.60 \%)$ \\
Total & $172(77.13 \%)$ & $51(22.87 \%)$ & 223 \\
\hline \multicolumn{4}{c}{ Note: *n $(\%)}$.
\end{tabular}

There were also statistically significant differences about the obtained performance according to the parents' gender who answered the questionnaire (Pearson's X2(2) $=6.96, p<.05$; Cramer's $V=.18$ ). When the mothers answered the questionnaire, the highest percentages of high performance (41\%) and medium (65\%) were registered, against a $36 \%$ of high and $65 \%$ of medium for fathers.

\section{Sports variables and its relation with sports performance}

As is established in Table 3, the fact of practicing a specific sport was also a variable that influenced the sports performance. Thus, some statistically significant differences were noted about the obtained performance according to the played sport (Pearson's $X 2(6)=21.88, p<.001$; Cramer's $V=.221$ ). The highest percentage of high performance was registered in basketball (53.33\%), while volleyball outnumbered the other sports in medium performance $(57.89 \%)$ and basketball outnumbered the other sports in low performance $(23.33 \%)$.

Furthermore, the sports performance breakdown according to the sports category (Table 4) revealed statistically significant differences in the pattern of sports performance according to the classification of the athletes in the categories of U-12, U-13 or U-15 (Pearson's $X 2(2)=22.91, p<.001$; Cramer's V $=.23$ ). The highest percentage of sports performance, established by sports categories, was in U-12 category (45.12\%9, the highest percentage for the medium performance was registered in U-15 category (76.47\%), and finally, the highest percentage of low performance was observed in U-13 category $(47.98 \%)$. 
Table 3. Frequencies and percentages of the sports performance variable according to the played sport.

\begin{tabular}{lccccc}
\hline \multicolumn{5}{c}{ Sports $^{*}$} \\
\hline Performance & Football & Basketball & Volleyball & Handball & Total \\
\hline High & $44(44.37 \%)$ & $16(53.33 \%)$ & $18(23.68 \%)$ & -- & $78(34.98 \%)$ \\
Medium & $49(44.95 \%)$ & $7(23.33 \%)$ & $44(57.89 \%)$ & $8(100 \%)$ & $108(48.43 \%)$ \\
Low & $16(14.68 \%)$ & $7(23.33 \%)$ & $14(18.42 \%)$ & -- & $37(16.60 \%)$ \\
Total & $109(48.88 \%)$ & $30(13.45 \%)$ & $76(34.08 \%)$ & $8(3.59 \%)$ & 223 \\
\hline
\end{tabular}
Note: ${ }^{*}(\%)$.

Table 4. Frequencies and percentages of the sports performance variable according to the sports category.

\begin{tabular}{lcccc}
\hline & \multicolumn{4}{c}{ Sports category } \\
\hline Performance & U-12 & U-13 & U-15 & Total \\
\hline High & $37(45.12 \%)$ & $41(38.32 \%)$ & -- & $78(34.98 \%)$ \\
Medium & $32(39.02 \%)$ & $50(46.73 \%)$ & $26(76.47 \%)$ & $108(48.43 \%)$ \\
Low & $13(15.85 \%)$ & $16(14.95 \%)$ & $8(23.53 \%)$ & $37(16.60 \%)$ \\
Total & $82(36.77 \%)$ & $107(47.98 \%)$ & $34(15.25 \%)$ & 223 \\
\hline \multicolumn{5}{c}{ Note: ${ }^{*}(\%)}$.
\end{tabular}

\section{Relation between the behaviour and conduct of parents in sports with the sports performance} A discriminant analysis was performed in which the seven dimensions of parental conducts from ACAPMD have been used as independent variables, assigning the sports performance as a dependent variable (with its three used categories: high, medium and low). By this way, a total of seven discriminant variables (or independent) and three groups of the discriminant variable (or dependent), will allow the calculation of a discriminant function.

In Table 5 it was established the obtained function with a self-value of $.04^{\text {a }}$, with a canonical correlation coefficient of .21 , which shows a proper discrimination capacity of the function. Moreover, the statistics Lambda of Wilks $=.96$, afterwards transformed into a distribution X2(2) $=11.01(p<.05)$, points that the obtained discriminant function is statistically significant. Furthermore, it was observed that the centroids of the group response to the next decreasing order, checking how the different groups pull away the mean of the total sample: high (-.28), medium (.19) and low (.04).

Table 5. Discriminant function to the sports performance according to ACAPMD.

\begin{tabular}{cccccccc}
\hline Function & Self-value & Explained variance & $\begin{array}{c}\text { Canonical } \\
\text { correlation }\end{array}$ & Lambda & X2 & df & p value \\
\hline 1 & $.04 a$ & 100 & .21 & .96 & 9.48 & 2 & .009 \\
\hline
\end{tabular}

\section{DISCUSSION AND CONCLUSIONS}

The aim of the present investigation was to analyse the relation between the behaviour and attitude of fathers and mothers of grassroots teams' players and other socio-demographic and sportive variables with their children's sports performance. After the obtained results, the initial hypothesis is confirmed.

Insightfully, it was expected that the parental behaviour and attitudes and other socio-demographic and sports variables could influence players' performance. This fact was confirmed, detecting statistically significant differences regarding the age, due to an age increasement will make more probable a high sports performance. Some statistically significant differences were also identified according to the geographical 
zone; therefore, the clubs of out of Palma registered the highest percentage of sports performance $(53.01 \%)$ and the lowest percentage of low sports performance (7.23\%). Regarding to the athletes' gender, some statistically significant differences were also observed, defining a higher percentage of high performance in men (43.02\%) and women highlighted in medium performance (62.74\%) and low (29.41\%).

There were also statistically significant differences related to the performance according to parents' gender answering the questionnaire, demonstrating that the highest percentages of high $(41 \%)$ and medium performance $(65 \%)$ were registered when mothers answered it. In that connection, Vasconcelos and Gomes (2015) point that in the motivational climate based on task, the highest technical and sports influence was performed by mothers, while parents highlighted for high levels of dissatisfaction with their children's sports performance.

Additionally, some statistically significant differences were noted about the obtained performance according to the played sport, due to basketball registered the highest percentage of high performance $(53.33 \%)$ and low performance $(23.33 \%)$, and volleyball highlighted in medium performance $(57.89 \%)$. There were also statistically significant differences according to the athletes' categories, because the highest percentage of sports performance was in U-12 (45.12\%), U-15's category highlighted in medium performance $(76.47 \%)$, and U-13's category highlighted in low performance (47.98\%). Similarly, Vasconcelos and Gomes (2015) show that youngest players (U-14) had more favourable opinions about parental involvement in sports, the achievement of the individual sports goals and a better evaluation of their performance in sports than older athletes.

In the same vein, González-García (2017) manifest that international success in sport is not related with neither protective mothers nor restrictive mothers. The same authors highlight that parenting education styles does not show relation with professional athletes, with the type of sport (individual or collective) or the training hours. Nevertheless, Vasconcelos and Gomes (2015) reinforce the importance of early parental involvement in sports for supporting the young athletes to perceive positively their sports performance. Likewise, these authors highlight that the athletes who have better sports performance indicators revealed more accompaniment to sports events and, that demonstrates that an improvement in sports performance comes throughout a high parental involvement in their children's sports.

Despite the results achieved, the present study presents some limitations related to include more sports, participants and geographical areas in the sample to provide more objective data for future investigations. In summary, the main conclusion that can be extracted of this study, is that the parental behaviour and attitudes and other socio-demographic and sport variables (sports category, parents' gender, players' gender, players' age, geographical zone and type of sport) can influence athletes' sports performance. Therefore, from a perspective focused on the practical implementation, it could be crucial for the positive sports experiences of children that socio-educational programs were carried out to reinforce the relevance of parental involvement in their children's sports independently of the obtained results or sports performance.

\section{CONFLICT OF INTEREST}

The authors of this article declare that there is no conflict of interest whatsoever. 


\section{FUNDING}

This research was conducted, in part, thanks to a grant (Values in sport) from Conselleria de Transparència, Cultura i Esport. Govern de les Illes Balears (Spain). Project number (06605).

\section{ACKNOWLEDGEMENT}

We are really grateful to all parents who participated in this study. Furthermore, we gratefully acknowledge the clubs which were involved in the present research.

\section{REFERENCES}

Caputo, E. L., Rombaldi, A. J., \& da Silva, M. C. (2017). Sintomas de estresse pré-competitivo em atletas adolescentes de handebol. Rev Bras Cienc Esporte, 39(1), 68-72. https://doi.org/10.1016/..rbce.2016.01.006

García-Gallego, C. \& Rubio de Lemus, P. (2013). Investigaciones ex post facto. In S. Fontes, C. GarcíaGallego, A. J. Garriga, M. C. Pérez-Llantada y E. Sarriá, Fundamentos de investigación en Psicología (pp. 255-273, $3^{\mathrm{a}}$ reimp.). Madrid: U.N.E.D.

Gómez-Díaz, A. J., Pallarés, J. G., Díaz, A., \& Bradley, P. S. (2013). Cuantificación de la carga física y psicológica en fútbol profesional: diferencias según el nivel competitivo y efectos sobre el resultado en competición oficial. Rev Psicol Deporte, 22(2), 0463-469.

González-García, H. (2017). Los estilos educativos parentales y variables personales que inciden en el rendimiento deportivo. Unpublished thesis. University Miguel Hernández, Elche, Spain.

González-García, H. \& Pelegrín, A. (2018). Familias Monoparentales, Rendimiento Deportivo y Horas de Entrenamiento-Ciencias del Ejercicio. Kronos, 17(2).

González Campos, G., Campos Mesa, M., \& Romero Granados, S. (2015). Análisis de la influencia de la evaluación del rendimiento en jugadores de un equipo de fútbol (Influence of the performance evaluation analysis of the football team players). Retos, 0(25), 85-89. Retrieved from https://recyt.fecyt.es/index.php/retos/article/view/34486

Hohepa, M., Scragg, R., Schofield, G., Kolt, G.S., \& Schaaf, D. (2007). Social support for youth physical activity: Importance of siblings, parents, friends and school support across a segmented school day. Int J Behav Nutr Phys Act, 4(54), 1-9. https://doi.org/10.1186/1479-5868-4-54

Fradejas, E. \& Espada-Mateos, M. (2018). How do psychological characteristics influence the sports performance of men and women? A study in school sports. J Human Sport Exercise, 13(4).858-872. https://doi.org/10.14198/hihse.2018.134.13

León, O. G. \& Montero, I. (2003). Métodos de Investigación en Psicología y Educación (3ª ed.). Madrid: Mcgraw-Hill.

López-Gullón, J. M., Torres-Bonete, M. D., Berengüi, R., Díaz, A., Martínez-Moreno, A., Morales-Baños, V., \& Pallarés, J. G. (2012). Rendimiento físico y psicológico en lucha olímpica: Predictores del éxito en lucha femenina. An Psicol, 28(1), 215-222.

Martínez-Moreno, A. (2017). Quality in elite sport. Analysis of strengths and weaknesses in psychological handball players. Cuad Psicol Deporte, 17(1), 19-24.

Pallarés, J. G., López-Gullón, J. M., Torres-Bonete, M. D., \& Izquierdo, M. (2012). Physical fitness factors to predict female Olympic wrestling performance and sex differences. J Strength Cond Res, 26(3), 794-803. https://doi.org/10.1519/jsc.0b013e31824741e7

Pulido, D., Borràs, P. A., \& Ponseti, F. J. (2019). La influencia y actuación de los padres en el fútbol cadete. Sport TK, 8(1), 51-56. https://doi.org/10.6018/sportk.362051 
Rachele, J. N., Cuddihy, T. F., Washington, T. L., \& McPhail, S. M. (2016). Adolescent's perceptions of parental influences on physical activity. Int $J$ Adolesc Medi Health, 21(3). https://doi.org/10.1515/ijamh-2015-0093

Simón, J. A. (2009). Percepciones de los deportistas sobre los factores que contribuyen a la excelencia en el deporte. Unpublished thesis. Unisversity of Castilla la Mancha, Toledo, Spain.

Strandbu, A., Stefansen, K., Smette I., \& Renslo-Sandvik, M. (2017). Young people's experiences of parental involvement in youth sport. Sport Educ Soc, 1, 66-77. https://doi.org/10.1080/13573322.2017.1323200

Vasconcelos, S. \& Gomes, A. (2015). Parental behavior, achievement goal and sport goals: A study with young athletes. Rev Iberoam Psicol Ejercicio Deporte, 10(2), 215-223.

Visscher, C., Elferink-Gemser, M. T., \& Lemmink, K. A. P. M. (2009). Role of parental support in sports success of talented young Dutch athletes. In M. J. Coelho e Silva, A. J. Figueiredo, M.T. ElferinkGemser, y R.M. Malina (Eds.), Youth Sports. Participation, Trainability and Readiness (pp. 103-116). Coimbra University Press: Portugal. https://doi.org/10.14195/978-989-26-0507-4_7

Witt, P. A. \& Dangi, T. B. (2018). Helping Parents be Better Youth Sport Coaches and Spectators. J Park Recreat Admi, 36(3), 200-208. https://doi.org/10.18666/JPRA-2018-V36-I3-8619

\section{(2) $\odot \Theta \Theta$}

This work is licensed under a Attribution-NonCommercial-NoDerivatives 4.0 International (CC BY-NC-ND 4.0). 